\title{
Enhanced increase of omega-3 index in healthy individuals with response to 4-week n-3 fatty acid supplementation from krill oil versus fish oil
}

Vanu R Ramprasath ${ }^{1,2}$, Inbal Eyal ${ }^{3}$, Sigalit Zchut ${ }^{3}$ and Peter JH Jones ${ }^{1,2^{*}}$

\begin{abstract}
Background: Due to structural differences, bioavailability of krill oil, a phospholipid based oil, could be higher than fish oil, a triglyceride-based oil, conferring properties that render it more effective than fish oil in increasing omega-3 index and thereby, reducing cardiovascular disease (CVD) risk.
\end{abstract}

Objective: The objective was to assess the effects of krill oil compared with fish oil or a placebo control on plasma and red blood cell (RBC) fatty acid profile in healthy volunteers.

Participants and methods: Twenty four healthy volunteers were recruited for a double blinded, randomized, placebocontrolled, crossover trial. The study consisted of three treatment phases including krill or fish oil each providing 600 mg of n-3 polyunsaturated fatty acids (PUFA) or placebo control, corn oil in capsule form. Each treatment lasted 4 wk and was separated by 8 wk washout phases.

Results: Krill oil consumption increased plasma ( $p=0.0043)$ and RBC ( $p=0.0011) n-3$ PUFA concentrations, including EPA and DHA, and reduced $n-6: n-3$ PUFA ratios (plasma: $p=0.0043, R B C: p=0.0143$ ) compared with fish oil consumption. Sum of EPA and DHA concentrations in RBC, the omega-3 index, was increased following krill oil supplementation compared with fish oil $(p=0.0143)$ and control $(p<0.0001)$. Serum triglycerides and HDL cholesterol concentrations did not change with any of the treatments. However, total and LDL cholesterol concentrations were increased following krill (TC: $p=0.0067, L D L: p=0.0143$ ) and fish oil supplementation (TC: $p=0.0028, L D L: p=0.0143$ ) compared with control.

Conclusions: Consumption of krill oil was well tolerated with no adverse events. Results indicate that krill oil could be more effective than fish oil in increasing n-3 PUFA, reducing n-6:n-3 PUFA ratio, and improving the omega-3 index.

Trial registration: ClinicalTrials.gov, NCT01323036

Keywords: Krill oil, Fish oil, Omega-3 index, Fatty acids, Human

\section{Background}

Epidemiological and clinical studies have shown various health benefits with consumption of fish and sea foods [1-6]. These positive health outcomes are attributed to the presence of $n-3$ polyunsaturated fatty acids (PUFA) in foods, including eicosapentaenoic acid (EPA) and docosahexaenoic acid (DHA). Krill oil, extracted from "Euphausia Superba", a species of the Southern ocean, is

\footnotetext{
* Correspondence: peter_jones@umanitoba.ca

${ }^{1}$ Richardson Centre for Functional Foods and Nutraceuticals, Winnipeg, Canada

${ }^{2}$ Department of Human Nutritional Sciences, University of Manitoba, Winnipeg, Canada

Full list of author information is available at the end of the article
}

a rich source of n-3 PUFA including EPA and DHA. Krill oil was found to be Generally Recognized as Safe (GRAS) by the American Food and Drug Administration (FDA) and obtained a Novel Food status from the European Union. Krill oil is comprised of n-3 PUFA, antioxidant carotenoid astaxanthin, vitamins $\mathrm{A}$ and $\mathrm{E}$, phospholipids (PL) as well as various other fatty acids $[7,8]$. Furthermore, numerous clinical and pre-clinical trials have shown that krill oil is safe and well tolerated, with no indication of adverse effects [9-13]. Consumption of krill oil increases plasma EPA and DHA levels in normal, overweight and obese participants [10].

Pre-clinical studies have shown that absorption of fatty acids attached to PL into target organs such as heart, 
brain and liver of animals, is better than fatty acids attached to glycerol as triglycerides (TG) [14]. Krill and fish oils differ in their composition where krill oil is comprised of PL and TG and fish oil is comprised of only TG. The primary PL in krill oil is phosphatidylcholine (PC), with $40 \%$ of the total fatty acids attached to the PC being EPA and DHA [15].

Results from animal and human studies suggest that krill oil is more effective compared with fish oil in improving CVD risk markers [11,16]. Metabolic effects of krill oil were reported to be similar to those of fish oil but at lower doses of EPA and DHA in healthy volunteers [17]. However, although superior bioavailability of n-3 PUFA in krill oil over fish oil was suggested, none of the studies managed to show improvement in absorption of n-3 fatty acids with krill oil over fish oil. At the most, data from a bioavailability study in humans showed a tendency for higher bioavailability for EPA after krill oil consumption compared with fish oil [18], however, this study tested an acute single dose of n-3 PUFA over $48 \mathrm{~h}$. To the best of our knowledge, no published literature has compared the effects of krill and fish oils after longer term consumption with a larger sample size using a randomized crossover design. Additionally, no randomized controlled trials have been conducted to compare the incorporation of n-3 PUFA to RBC membranes after consumption of krill and fish oil.

The objective of the present trial was therefore to assess the effects of krill oil compared with fish oil and a placebo control (corn oil) on plasma and RBC fatty acid profile in healthy volunteers following 4 wk of supplementation. Specific objectives included assessment and comparison of serum lipid profile in healthy volunteers at baseline and following $4 \mathrm{wk}$ of intervention with krill versus fish oils.

\section{Results}

Thirty four participants (20 males and 14 females) were screened out of which 24. (12 males and 12 females) were eligible and enrolled into the study. All participants completed the study and as such there were no drop outs. Table 1 shows baseline characteristics of the participants involved. Participants were healthy and of age, $28.2 \pm 5.4$ y with body weight and BMI of $68.3 \pm 11.9$ (kg) and $23.8 \pm 3$ (body weight in $\mathrm{kg} /$ height in $\mathrm{M}^{2}$ ) respectively. Vital signs including body weight, systolic and diastolic blood pressure and heart rate were within normal ranges. No significant changes were observed for body weight, BMI, waist circumference, systolic and diastolic blood pressure or heart rates after treatment with krill or fish oil compared with control phase (Data not shown).

Initial statistical tests that were carried out aimed to test the efficiency of the washout period. No significant
Table 1 Baseline characteristics of participants $(n=24)$

\begin{tabular}{|c|c|c|}
\hline Parameter & Mean & STD \\
\hline Age $(Y)$ & 28.23 & 5.35 \\
\hline Body weight (Kg) & 68.27 & 11.92 \\
\hline Height (m) & 1.69 & 0.07 \\
\hline BMI $\left(\mathrm{kg} / \mathrm{m}^{2}\right)$ & 23.76 & 2.96 \\
\hline Waist $(\mathrm{cm})$ & 78.28 & 8.25 \\
\hline Hip (cm) & 92.07 & 5.18 \\
\hline Waist/Hip ratio & 0.85 & 0.08 \\
\hline Systolic BP (mmHg) & 108.07 & 10.21 \\
\hline Diastolic BP (mmHg) & 72.01 & 7.69 \\
\hline Heart rate & 69.17 & 9.28 \\
\hline TG (mg/dL) & 91.23 & 36.58 \\
\hline $\mathrm{HDL}(\mathrm{mg} / \mathrm{dL})$ & 53.16 & 13.45 \\
\hline LDL (mg/dL) & 103.51 & 22.77 \\
\hline Total cholesterol (mg/dL) & 175.61 & 23.39 \\
\hline WBC count $\left(X 10^{9} / L\right)$ & 5.93 & 1.20 \\
\hline $\mathrm{RBC}\left(\mathrm{X} 10^{12} / \mathrm{L}\right)$ & 4.70 & 0.51 \\
\hline Hematocrit (L/L) & 0.41 & 0.04 \\
\hline Hemoglobin (g/L) & 141.33 & 15.38 \\
\hline Platelet count (X109/L) & 219.88 & 34.53 \\
\hline Neutrophils (\%) & 53.09 & 7.81 \\
\hline Lymphocytes (\%) & 36.25 & 7.81 \\
\hline Monocytes (\%) & 8.14 & 2.16 \\
\hline Eosinophils (\%) & 2.16 & 1.13 \\
\hline Basophils (\%) & 0.48 & 0.17 \\
\hline MCV (fl.) & 88.10 & 6.74 \\
\hline $\mathrm{MCH}(\mathrm{pg})$ & 30.21 & 2.69 \\
\hline MCHC (g/L) & 342.46 & 6.09 \\
\hline
\end{tabular}

differences were seen between baselines of different phases for all parameters measured in plasma and RBC which indicate that the washout period was sufficient to wash out or revert back the levels of n-3 fatty acids in both the plasma and the RBC back to baseline levels.

Table 2 shows the plasma fatty acid profiles of the participants during the study. Increased plasma EPA and DHA levels ( $\mathrm{p}<0.0001$ and $\mathrm{p}<0.0002$, respectively) were observed with both krill and fish oil treatments compared with control. Krill oil consumption elevated $(p=$ 0.0043) plasma EPA levels compared with fish oil. Plasma concentrations of DPA were found to be elevated after treatment with both krill oil $(\mathrm{p}=0.011)$ and fish oil $(\mathrm{p}=0.014)$ compared with control. Levels of total $\mathrm{n}-3$ fatty acids were also increased $(p<0.0001)$ after supplementation of krill oil and fish oil compared with control. In addition, krill oil consumption increased the level of total $n-3$ PUFA compared with fish oil $(p=0.0043)$. Similar results were obtained for the sum of EPA and DHA 
Table 2 Plasma composition of fatty acids and their changes with different interventions

\begin{tabular}{|c|c|c|c|c|c|c|c|}
\hline \multirow[t]{2}{*}{ Parameter } & \multirow[t]{2}{*}{ Treatment } & \multicolumn{2}{|c|}{ Baseline } & \multicolumn{2}{|c|}{ End-Point } & \multicolumn{2}{|c|}{ Change } \\
\hline & & Mean \pm STD & P. value ${ }^{1}$ & Mean \pm STD & P. value ${ }^{1}$ & Mean \pm STD & P. value ${ }^{1}$ \\
\hline \multirow[t]{3}{*}{ EPA } & Krill oil & $0.80 \pm 0.31$ & 0.5134 & $1.97 \pm 0.58^{* \#}$ & $<0.0001$ & $1.17 \pm 0.52^{* \#}$ & $<0.0001$ \\
\hline & Fish oil & $0.82 \pm 0.36$ & & $1.54 \pm 0.69^{*}$ & & $0.71 \pm 0.46^{*}$ & \\
\hline & Corn oil & $0.86 \pm 0.36$ & & $0.79 \pm 0.43$ & & $-0.06 \pm 0.36$ & \\
\hline \multirow[t]{3}{*}{ DPA } & Krill oil & $0.61 \pm 0.31$ & 0.9087 & $0.79 \pm 0.27^{*}$ & 0.0048 & $0.15 \pm 0.23^{*}$ & 0.0076 \\
\hline & Fish oil & $0.64 \pm 0.24$ & & $0.68 \pm 0.28$ & & $0.04 \pm 0.18^{*}$ & \\
\hline & Corn oil & $0.64 \pm 0.25$ & & $0.61 \pm 0.16$ & & $-0.03 \pm 0.19$ & \\
\hline \multirow[t]{3}{*}{ DHA } & Krill oil & $2.90 \pm 0.58$ & 0.5134 & $3.86 \pm 0.89^{*}$ & $<0.0001$ & $0.96 \pm 0.69^{*}$ & $<0.0001$ \\
\hline & Fish oil & $2.88 \pm 0.59$ & & $3.72 \pm 0.66^{*}$ & & $0.84 \pm 0.55^{*}$ & \\
\hline & Corn oil & $3.03 \pm 0.66$ & & $2.80 \pm 0.60$ & & $-0.24 \pm 0.69$ & \\
\hline \multirow[t]{3}{*}{ Total n-3 PUFA } & Krill oil & $4.97 \pm 0.69$ & 0.8465 & $7.20 \pm 1.35^{* \#}$ & $<0.0001$ & $2.23 \pm 1.13^{* \#}$ & $<0.0001$ \\
\hline & Fish oil & $4.96 \pm 0.59$ & & $6.51 \pm 0.97^{*}$ & & $1.55 \pm 0.83^{*}$ & \\
\hline & Corn oil & $5.13 \pm 0.95$ & & $4.79 \pm 0.63$ & & $-0.34 \pm 0.86$ & \\
\hline \multirow[t]{3}{*}{$E P A+D H A$} & Krill oil & $3.70 \pm 0.63$ & 0.7470 & $5.83 \pm 1.31^{* \#}$ & $<0.0001$ & $2.13 \pm 1.02^{* \#}$ & $<0.0001$ \\
\hline & Fish oil & $3.70 \pm 0.65$ & & $5.26 \pm 0.95^{*}$ & & $1.55 \pm 0.73^{*}$ & \\
\hline & Corn oil & $3.89 \pm 0.85$ & & $3.59 \pm 0.59$ & & $-0.30 \pm 0.76$ & \\
\hline \multirow[t]{3}{*}{ n-6:n-3 ratio } & Krill oil & $7.06 \pm 1.18$ & 0.5818 & $4.88 \pm 1.37^{* \#}$ & $<0.0001$ & $-2.17 \pm 1.05^{* \#}$ & $<0.0001$ \\
\hline & Fish oil & $7.21 \pm 0.93$ & & $5.32 \pm 0.99^{*}$ & & $-1.89 \pm 0.91^{*}$ & \\
\hline & Corn oil & $7.12 \pm 1.4$ & & $7.57 \pm 1.06$ & & $0.44 \pm 0.95$ & \\
\hline \multirow[t]{3}{*}{ Total SFA } & Krill oil & $43.46 \pm 1.85$ & 0.3247 & $43.03 \pm 1.63$ & 0.0226 & $-0.43 \pm 1.93$ & 0.0787 \\
\hline & Fish oil & $42.92 \pm 1.32$ & & $43.65 \pm 1.06^{*}$ & & $0.73 \pm 1.44$ & \\
\hline & Corn oil & $42.13 \pm 4.74$ & & $42.53 \pm 2.13$ & & $0.40 \pm 5.04$ & \\
\hline \multirow[t]{3}{*}{ Total MUFA } & Krill oil & $17.23 \pm 2.93$ & 0.8825 & $16.29 \pm 2.42^{*}$ & 0.0226 & $-0.94 \pm 2.86$ & 0.8465 \\
\hline & Fish oil & $16.84 \pm 2.47$ & & $16.06 \pm 1.74^{*}$ & & $-0.78 \pm 2.51$ & \\
\hline & Corn oil & $17.25 \pm 3.06$ & & $16.97 \pm 2.21$ & & $-0.29 \pm 3.11$ & \\
\hline \multirow[t]{3}{*}{ Total PUFA } & Krill oil & $39.31 \pm 2.39$ & 0.2748 & $40.68 \pm 2.06$ & 0.8825 & $1.36 \pm 2.58$ & 0.9592 \\
\hline & Fish oil & $40.24 \pm 1.98$ & & $40.28 \pm 1.73$ & & $0.05 \pm 2.16$ & \\
\hline & Corn oil & $40.62 \pm 3.92$ & & $40.51 \pm 2.22$ & & $-0.11 \pm 4.69$ & \\
\hline \multirow[t]{3}{*}{ Total n-6 PUFA } & Krill oil & $34.35 \pm 2.41$ & 0.6873 & $33.48 \pm 2.26^{*}$ & 0.0007 & $-0.87 \pm 2.08$ & 0.0226 \\
\hline & Fish oil & $35.28 \pm 1.87$ & & $33.77 \pm 1.75^{*}$ & & $-1.51 \pm 2.07^{*}$ & \\
\hline & Corn oil & $35.49 \pm 3.62$ & & $35.72 \pm 2.14$ & & $0.22 \pm 4.09$ & \\
\hline
\end{tabular}

Values are expressed as percentage of total fatty acids except the $n-6: n-3$ ratio $(n=24)$. ${ }^{1}$ Friedman Test was used to test if there is a significant difference between treatment groups regarding the results in baseline, end-point and change. ${ }^{*}$ and ${ }^{\#}$ indicate significant difference compared with corn and fish oil treatments respectively.

where both krill and fish oils increased levels of EPA + DHA in plasma $(\mathrm{p}<0.0001)$ compared with control. Furthermore, krill oil increased the plasma concentrations of EPA + DHA compared with fish oil ( $\mathrm{p}=0.0011)$.

No significant changes in total saturated fatty acids (SFA), PUFA and mono-unsaturated fatty acids (MUFA) concentrations were observed between the three treatments except for an increase in SFA and a decrease in MUFA with fish oil intake $(p=0.0143)$ compared with control (Additional file 1: Table S1). A decrease in MUFA was also observed after krill oil intake $(\mathrm{p}=0.041)$ compared with control. Total n-6 PUFA concentrations were reduced after both krill $(\mathrm{p}=0.0043)$ and fish $(\mathrm{p}=$
0.0011) oil treatments, compared with control. However, no significant differences were observed in the n-6 PUFA concentrations between krill and fish oil treatments. Both krill and fish oil treatments reduced $(\mathrm{p}<$ 0.0001 ) the ratio between $n-6$ and $n-3$ fatty acids compared with control. The ratio of $n-6: n-3$ fatty acids was found to be reduced $(p=0.0043)$ by krill oil treatment compared with fish oil treatment.

Table 3 shows the RBC fatty acid profiles of the participants during the study. Red blood cell levels of EPA were elevated $(\mathrm{p}<0.0001)$ following both krill and fish oil treatment compared with control treatment. On the other hand, the RBC EPA level was higher $(\mathrm{P}=0.0011)$ 
following krill oil treatment compared with fish oil. Krill oil also elevated the RBC levels of DHA $(p=0.0011)$ compared with control. However, no significant differences existed in the DHA levels after fish oil treatment compared with control. Sum of EPA and DHA in RBC membranes (as percent of total fatty acid content), which is denoted as omega-3 index, increased following krill $(\mathrm{p}<0.0001)$ and fish oil consumption $(\mathrm{p}=0.0043)$ compared with control. Interestingly, krill oil treatment elevated the omega-3 index compared with fish oil treatment $(p=0.0143)$. The change in omega-3 index after consumption of krill oil was two-fold higher than fish oil (1.04\% and $0.47 \%$ following krill and fish oil treatments respectively; $p=0.0043)$. Similarly, krill oil treatment led to an increase in RBC DPA levels compared with fish ( $\mathrm{p}=$ $0.0412)$ and control oil $(\mathrm{p}=0.0412)$ supplementation. Treatment with fish oil failed to affect DPA levels in the RBC. Both krill and fish oil treatments reduced $(\mathrm{p}=$ 0.0011 ) total $n-6$ fatty acid levels compared with control. No differences in the n-6 PUFA concentrations were observed with krill oil compared with fish oil intake. Similar to plasma fatty acid results, no significant changes with RBC total PUFA, MUFA and SFA concentrations were seen between the three treatment phases. As expected, krill and fish oil treatments increased RBC n-3 PUFA levels $(\mathrm{p}<0.0001$ and $\mathrm{p}=0.0143$ for krill oil and fish oil

Table 3 RBC composition of fatty acids and their changes with different interventions

\begin{tabular}{|c|c|c|c|c|c|c|c|}
\hline \multirow[t]{2}{*}{ Parameter } & \multirow[t]{2}{*}{ Treatment } & \multicolumn{2}{|c|}{ Baseline } & \multicolumn{2}{|c|}{ End-Point } & \multicolumn{2}{|c|}{ Change } \\
\hline & & Mean \pm STD & P. value ${ }^{1}$ & Mean \pm STD & P. value $^{1}$ & Mean \pm STD & P. value $^{1}$ \\
\hline \multirow[t]{3}{*}{ EPA } & Krill oil & $0.82 \pm 0.23$ & 0.8825 & $1.48 \pm 0.38^{* \#}$ & $<0.0001$ & $0.66 \pm 0.29^{* \#}$ & $<0.0001$ \\
\hline & Fish oil & $0.80 \pm 0.23$ & & $1.10 \pm 0.25^{*}$ & & $0.30 \pm 0.26^{*}$ & \\
\hline & Corn oil & $0.80 \pm 0.21$ & & $0.74 \pm 0.22$ & & $-0.05 \pm 0.16$ & \\
\hline \multirow[t]{3}{*}{ DPA } & Krill oil & $2.24 \pm 0.27$ & 0.7470 & $2.42 \pm 0.21^{* \#}$ & 0.0421 & $0.18 \pm 0.23$ & 0.0787 \\
\hline & Fish oil & $2.29 \pm 0.28$ & & $2.28 \pm 0.24$ & & $-0.01 \pm 0.29$ & \\
\hline & Corn oil & $2.25 \pm 0.34$ & & $2.26 \pm 0.27$ & & $0.00 \pm 0.31$ & \\
\hline \multirow[t]{3}{*}{ DHA } & Krill oil & $4.12 \pm 0.83$ & 0.2140 & $4.50 \pm 0.75^{*}$ & 0.0039 & $0.38 \pm 0.44^{* \#}$ & 0.0002 \\
\hline & Fish oil & $4.16 \pm 0.73$ & & $4.34 \pm 0.83$ & & $0.17 \pm 0.64$ & \\
\hline & Corn oil & $4.21 \pm 0.89$ & & $4.12 \pm 0.72$ & & $-0.09 \pm 0.56$ & \\
\hline \multirow[t]{3}{*}{ Total n-3 PUFA } & Krill oil & $7.52 \pm 1.03$ & 0.4531 & $8.74 \pm 1.08^{* \#}$ & $<0.0001$ & $1.22 \pm 0.77^{* \#}$ & $<0.0001$ \\
\hline & Fish oil & $7.59 \pm 0.86$ & & $8.04 \pm 1.00^{*}$ & & $0.45 \pm 1.00^{*}$ & \\
\hline & Corn oil & $7.59 \pm 1.22$ & & $7.47 \pm 0.95$ & & $-0.11 \pm 0.90$ & \\
\hline \multirow[t]{3}{*}{$\mathrm{EPA}+\mathrm{DHA}$} & Krill oil & $4.94 \pm 0.97$ & 0.6873 & $5.97 \pm 1.03^{* \#}$ & $<0.0001$ & $1.04 \pm 0.59^{* \#}$ & $<0.0001$ \\
\hline & Fish oil & $4.96 \pm 0.79$ & & $5.43 \pm 0.97^{*}$ & & $0.47 \pm 0.77^{*}$ & \\
\hline & Corn oil & $5.00 \pm 1.02$ & & $4.86 \pm 0.80$ & & $-0.14 \pm 0.61$ & \\
\hline \multirow[t]{3}{*}{$n-6: n-3$ ratio } & Krill oil & $4.17 \pm 0.68$ & 0.4169 & $3.45 \pm 0.59^{* \#}$ & $<0.0001$ & $-0.72 \pm 0.43^{* \#}$ & $<0.0001$ \\
\hline & Fish oil & $4.08 \pm 0.47$ & & $3.77 \pm 0.52^{*}$ & & $-0.31 \pm 0.41^{*}$ & \\
\hline & Corn oil & $4.14 \pm 0.84$ & & $4.20 \pm 0.60$ & & $0.06 \pm 0.56$ & \\
\hline \multirow[t]{3}{*}{ Total SFA } & Krill oil & $43.55 \pm 1.98$ & 0.6065 & $43.12 \pm 1.86$ & 0.1969 & $-0.43 \pm 1.86$ & 0.0613 \\
\hline & Fish oil & $43.58 \pm 1.97$ & & $44.22 \pm 2.05$ & & $0.64 \pm 2.26$ & \\
\hline & Corn oil & $43.62 \pm 2.44$ & & $43.34 \pm 1.51$ & & $-0.29 \pm 1.92$ & \\
\hline \multirow[t]{3}{*}{ Total MUFA } & Krill oil & $18.21 \pm 1.17$ & 0.8825 & $18.55 \pm 2.33$ & 0.5134 & $0.34 \pm 2.13$ & 0.3114 \\
\hline & Fish oil & $18.17 \pm 1.39$ & & $17.82 \pm 1.31$ & & $-0.35 \pm 1.03$ & \\
\hline & Corn oil & $18.34 \pm 1.49$ & & $18.30 \pm 1.32$ & & $-0.03 \pm 0.93$ & \\
\hline \multirow[t]{3}{*}{ Total PUFA } & Krill oil & $38.25 \pm 2.33$ & 0.6065 & $38.33 \pm 2.02$ & 0.7470 & $0.08 \pm 1.98$ & 0.5818 \\
\hline & Fish oil & $38.25 \pm 2.38$ & & $37.96 \pm 2.45$ & & $-0.29 \pm 2.59$ & \\
\hline & Corn oil & $38.05 \pm 2.73$ & & $38.36 \pm 2.03$ & & $0.32 \pm 2.26$ & \\
\hline \multirow[t]{3}{*}{ Total n-6 PUFA } & Krill oil & $30.73 \pm 2.01$ & 0.1969 & $29.59 \pm 2.01^{*}$ & 0.0107 & $-1.14 \pm 1.66^{*}$ & 0.0003 \\
\hline & Fish oil & $30.66 \pm 1.96$ & & $29.92 \pm 2.13^{*}$ & & $-0.74 \pm 1.86^{*}$ & \\
\hline & Corn oil & $30.46 \pm 2.13$ & & $30.89 \pm 1.79$ & & $0.43 \pm 1.65$ & \\
\hline
\end{tabular}


respectively) and reduced $n-6: n-3$ ratio (krill: $\mathrm{p}<0.0001$, fish: $\mathrm{p}=0.0143$ ) compared with control. Krill oil treatment also elevated the total n-3 PUFA concentrations ( $\mathrm{p}=$ $0.0011)$ and reduced the $n-6: n-3$ ratio $(p=0.0143)$ compared with the fish oil treatment. Total n-6 PUFA was found to be reduced with both krill and fish oil phases $(\mathrm{p}=0.0143)$ compared to control. Furthermore, concentrations of n-6 PUFA were not significantly different between krill and fish oil phases. Additionally, no significant changes in total SFA, PUFA and MUFA concentrations were observed between the three treatments in the RBC (Additional file 1: Table S2).

Serum lipid concentrations of participants during the study are portrayed in Table 4. Serum TG and HDL cholesterol levels did not change across the three treatments. However, total and LDL cholesterol concentrations were found to be higher after krill oil $(p=0.0067$; $\mathrm{p}=0.0143$, for total and LDL cholesterol, respectively) supplementation compared with control. Similarly, fish oil consumption increased total and LDL cholesterol levels $(p=0.0028 ; p=0.0143$, for total and LDL cholesterol, respectively) compared with control oil supplementation. No differences were observed either in serum total or LDL cholesterol concentrations or in the TC/HDL ratio when comparing krill and fish oil consumption.

Overall, no differences were observed between baselines of either the fatty acid tested in each treatment or the order of treatments or placebo received by the participants. In addition, no gender or age effect was found in any of the parameters analyzed. Safety with consumption

\begin{tabular}{|c|c|c|c|}
\hline Parameters & Treatment & $\begin{array}{l}\text { Baseline } \\
\text { (mg/dL) }\end{array}$ & $\begin{array}{l}\text { Endpoint } \\
\text { (mg/dL) }\end{array}$ \\
\hline \multirow[t]{3}{*}{$\overline{\mathrm{TG}}$} & Krill oil & $101.10 \pm 10.53$ & $99.86 \pm 8.32$ \\
\hline & Fish oil & $86.69 \pm 6.73$ & $89.20 \pm 7.31$ \\
\hline & Corn oil & $103.41 \pm 9.84$ & $103.45 \pm 10.53$ \\
\hline \multirow[t]{3}{*}{$\mathrm{HDL}$} & Krill oil & $55.74 \pm 2.91$ & $60.90 \pm 2.91$ \\
\hline & Fish oil & $56.71 \pm 2.84$ & $58.81 \pm 2.76$ \\
\hline & Corn oil & $56.22 \pm 3.38$ & $58.00 \pm 3.07$ \\
\hline \multirow[t]{3}{*}{ LDL } & Krill oil & $93.05 \pm 4.66$ & $101.31 \pm 6.20^{*}$ \\
\hline & Fish oil & $94.78 \pm 5.53$ & $102.43 \pm 5.81^{*}$ \\
\hline & Corn oil & $95.03 \pm 4.82$ & $93.25 \pm 5.29$ \\
\hline \multirow[t]{4}{*}{ Total cholesterol } & Krill oil & $168.85 \pm 5.45$ & $181.90 \pm 6.75^{*}$ \\
\hline & Fish oil & $169.65 \pm 5.60$ & $179.22 \pm 5.78^{*}$ \\
\hline & Corn oil & $172.55 \pm 5.69$ & $172.24 \pm 5.99$ \\
\hline & Krill oil & $3.21 \pm 0.20$ & $3.16 \pm 0.22$ \\
\hline \multirow[t]{2}{*}{ Total cholesterol/HDL ratio } & Fish oil & $3.21 \pm 0.23$ & $3.24 \pm 0.21$ \\
\hline & Corn oil & $3.29 \pm 0.21$ & $3.17 \pm 0.21$ \\
\hline
\end{tabular}

Values are expressed as Mean \pm SEM. $\mathrm{n}=24$. ${ }^{*}$ denotes significance compared with corn oil treatment. of krill and fish oil were determined by measuring blood parameters including WBC, RBC, hematocrit, hemoglobin, platelet count, neutrophils, lymphocytes, monocytes, eosinophils, basophils, $\mathrm{MCV}, \mathrm{MCH}$ and $\mathrm{MCHC}$ values. No significant differences were found in any of the above parameters with either krill or fish oil supplementation compared with control (Data not shown).

Medical history and physical examination revealed that none of the participants had any health problems or concerns which are known to affect study outcomes. The study physician recorded and compared the health status of participants at each visit. None of the participants during the study showed major changes in their health status related to the trial.

No adverse or serious adverse events related to the treatments were reported during the period of the study. During the study one participant experienced a skin infection, one had an allergic reaction and another participant had her appendix surgically removed. All these three events occurred during the washout periods and were deemed not related to the study. None of the participants consumed any concomitant medications or supplements that are known to affect study outcomes. All participants reported followed guidelines not to eat more than one serving per mo of fish or sea food. None of the participants exceeded the limit of fish or sea food consumption during intervention or washout periods. Participants consumed the study capsules regularly according to the instructions. Participants were of high compliance with capsule consumption which is evident from the calculated self-reported compliance on capsule consumption. The compliance ratings for capsule consumption during krill and fish oil interventions were $95.79 \pm 6.87 \%$ and $96.91 \pm 5.86 \%$, respectively. During the control oil intervention, the compliance was $96.89 \pm 4.27 \%$.

Krill oil treatment failed to produce any gastrointestinal symptoms compared with fish oil or placebo control interventions, except for burping and aftertaste (Table 5). Four participants reported mild and three moderate burping after krill oil consumption, whereas only two participants reported burping (one mild and one moderate) after consuming fish oil or placebo control intervention. Similarly, 7 participants reported having aftertaste (six mild and one moderate) with krill oil consumption. Three participants reported having a mild aftertaste with fish oil consumption, however, none of them felt any aftertaste with control oil consumption. Two participants experienced mild hiccupping during fish oil consumption but no hiccupping was reported with krill oil or placebo control intervention.

\section{Discussion}

The current findings show, for the first time, that consumption of $3 \mathrm{~g} / \mathrm{d}$ krill oil for $4 \mathrm{wk}$ increases the plasma 
Table 5 Gastrointestinal responses from participants

\begin{tabular}{|c|c|c|c|}
\hline Gl symptoms & $\begin{array}{c}\text { Krill oil } \\
\text { (No. of participants) }\end{array}$ & $\begin{array}{c}\text { Fish oil } \\
\text { (No. of participants) }\end{array}$ & $\begin{array}{c}\text { Corn oil } \\
\text { (No. of participants) }\end{array}$ \\
\hline Hiccup & - & Mild- 2 & - \\
\hline \multirow[t]{2}{*}{ Burping } & Mild - 4 & Mild - 1 & Mild - 1 \\
\hline & Moderate - 3 & Moderate - 1 & Moderate - 1 \\
\hline Nausea & - & - & - \\
\hline Vomiting & - & - & - \\
\hline Indigestion & - & Mild - 1 & Mild - 1 \\
\hline Stomach/abdominal pain & - & Mild - 1 & - \\
\hline Constipation & Mild - 1 & - & - \\
\hline Diarrhea & - & - & - \\
\hline Flatulence & Mild - 1 & Mild - 2 & Mild - 1 \\
\hline \multirow[t]{2}{*}{ Abdominal bloating } & Mild - 2 & Mild - 1 & Mild - 1 \\
\hline & & & Moderate - 1 \\
\hline Cramping & - & - & - \\
\hline Heartburn & - & - & Mild - 1 \\
\hline \multirow[t]{2}{*}{ After taste } & Mild - 6 & Mild - 3 & - \\
\hline & Moderate - 1 & & \\
\hline
\end{tabular}

and RBC concentrations of total n-3 PUFA, EPA, and the sum of EPA and DHA compared with fish and corn oil in healthy humans. Krill oil consumption also resulted in a significant decrease in the total n-6:n-3 PUFA ratio and increased the omega- 3 index compared with fish oil and control treatments. Fish oil treatment also significantly increased the plasma and RBC concentrations of total n-3 PUFA and EPA and decreased the total n-6:n-3 PUFA ratio compared with control. These results indicate that bioavailability of krill oil n-3 PUFA might be more pronounced compared with that of fish oil, likely due to the structural differences between these two marine oils. Moreover, both krill and fish oil were well tolerated by participants and caused no adverse effects which shows the safe nature of krill oil. According to our knowledge, the current study is the first to compare the effects of krill and fish oils on fatty acid profile in plasma and RBC after $4 \mathrm{wk}$ of consumption, using a randomized crossover design.

In the present study, krill oil supplementation for $4 \mathrm{wk}$ resulted in a substantial increase in EPA total n-3 PUFA and the sum of EPA and DHA levels in the plasma, compared with fish oil treatment although fish oil also increased the plasma EPA, DHA and total n-3 PUFA compared with control. Since both krill and fish oil treatments delivered the same amount of total n-3 PUFA, these findings indicate that the bioavailability of n-3 PUFA from krill oil might be higher than that of n-3 PUFA from fish oil. Several studies were carried out attempting to test the hypothesis that $\mathrm{n}-3$ fatty acids will be better absorbed as PL based oil, such as krill oil, compared with TG based oil, such as fish oil, [10,17] or ethyl-esters [18]. However all of these trials, although using different study designs, duration, selection criteria and concentrations of the n-3 PUFA, consistently show a non-significant increased bioavailability of $n-3$ PUFA from krill oil compared with fish oil. It is very likely that the reason for the poor results presented thus far is due to use of study designs not suitable for absorption studies.

Krill oil supplementation reduced plasma n-6 PUFA, along with increases in n-3 PUFA concentrations, resulting in decreased n-6:n-3 PUFA ratio compared with fish oil treatment. Furthermore, fish oil intake also reduced the plasma n-6 PUFA and n-6:n-3 PUFA ratio compared with control. In the current study, the lower plasma n-6 PUFA and n-6:n-3 PUFA ratio with krill oil intake compared with fish oil intake might also be due to differences in fatty acid composition of the krill and fish oils used. The n-6 PUFA content of the krill oil was low $(1.73 \mathrm{~g} / 100 \mathrm{~g}$ oil $)$ compared with fish oil $(21.95 \mathrm{~g} / 100 \mathrm{~g}$ oil). The current study did not control the n- 6 PUFA concentrations between krill and fish oil. However, even with higher n-6 PUFA content, fish oil treatment actually significantly reduced the plasma concentrations of n-6 PUFA. Furthermore, n-6 PUFA consumption by the participants was not controlled although n-3 PUFA consumption was well controlled during the intervention period. Amounts of n-6 PUFA in the diet might be higher than the difference in the amount between the different treatment oils. Hence, it is understandable that consumption of both krill and fish oils resulted in 
reductions of n-6 PUFA which might also contribute in decreased n-6:n-3 ratio along with elevations of total $n-3$ PUFA concentration.

Reduction in n-6:n-3 PUFA ratio after krill oil consumption observed in the current study was in line with previous reports analyzing the $n-6: n-3$ ratio with intake of $n-3$ rich oils $[10,17,19]$. It has been shown that $n-6: n-$ 3 PUFA ratio is strongly associated with CVD risk [20]. Hence, krill oil supplementation could be recommended to increase the n-3 PUFA, omega-3 index and reduce the n-6:n-3 PUFA ratio thereby reducing the risk of CVD. Indeed, it is currently recommended that consumption of 1-3 g/d of EPA and DHA through fish oil reduces CVD risk [21,22]. However, evidence from epidemiological studies on effects of fish oil on CVD is inconsistent with totally negative association $[3,23]$ or no effect $[24,25]$ having been identified. Bioavailability of $n-$ 3 PUFA could play a major role for these discrepancies. It has been shown that DHA is highly absorbed when delivered by PL compared with fish oil in mice deprived of essential fatty acids [26]. Additional in vivo studies using animal models demonstrated that the level of absorption of DHA into target tissues, such as brain and heart, is affected by the source of the DHA. It was shown that PL-bound DHA deliver the DHA to brains hearts and liver in different animal models including mice, rats and baboons more efficiently than TG-bound DHA [14,26-28]. In humans, Carnielli et al. tested the ability of preterm babies to absorb DHA given in formulas enriched with DHA in PL form or TG forms [29]. The results showed that DHA in a PL form was absorbed significantly better compared than in a TG form.

Sum of EPA and DHA in RBC has been considered as the highly valuable omega- 3 index and was demonstrated to serve as a risk factor for death from CVD $[2,30,31]$. In the current study, krill oil consumption resulted in an elevated omega-3 index compared with consumption of fish oil and control oil treatments, emphasizing the efficiency and higher bioavailability of krill oil over fish oil. Concentrations of EPA and DHA in RBC have a longer half-life of about 4-6 times compared with plasma EPA and DHA [32], thus reflecting long term intakes of n-3 PUFA status of individuals [2]. Measurement of fatty acids in $\mathrm{RBC}$ reflects the tissue composition and the concentrations of the EPA and DHA in RBC which are not influenced by dyslipidemia [30]. Increased n-3 PUFA concentrations in RBC have been shown to be associated with reduced risk of CVD [2,33-35].

In the current study, both krill and fish oil treatments failed to affect serum HDL and TG concentrations compared with control. No significant differences were seen with effects of krill oil compared with fish oil consumption on serum lipid levels. Indeed, both krill and fish oils increased serum total and LDL cholesterol concentrations compared with control. Results are not surprising as the participants used in the study were normolipidemic healthy individuals. Studies have shown that higher dosages of about 2-4 g/d of EPA and DHA were needed to bring significant reductions in serum lipid concentrations of normolipidemic participants [5,36,37]. Although krill oil supplementation has demonstrated hypolipidemic activity in some studies, this effect is found to be more pronounced with participants with hyperlipidemia $[11,36,38]$. Similar results were found in previous studies with normolipidemic participants in whom there was no effect on serum lipids $[10,17,39]$. Reduction of serum TG by $n-3$ PUFA also depends on their baseline concentrations $[36,38,40]$. Supplementation of $1-4 \mathrm{~g} / \mathrm{d}$ of EPA reduced serum TG in hyperlipidemic participants compared with normolipidemics [41-44]. Consumption of n-3 PUFA from fish oil increased the diameter of LDL particles [45] and reduced the number of small dense LDL particles while increasing LDL particle size which could be the reasons for the increase in LDL in some studies [46,47].

In regards to safety parameters, krill oil supplementation of $4 \mathrm{wk}$ was well tolerated, with participants experiencing no adverse events. No changes were seen in vital signs, anthropometric measures and hematological variables or concerns by the study physician after the physical examination between the different treatments. Also, treatment with krill oil did not change any of the gastrointestinal symptoms compared with fish oil or control intervention except mild burping and aftertaste. The findings on safety parameters along with the high compliance from participants indicate the safety of krill oil consumption as shown by other studies $[10,17]$.

\section{Strengths of the study}

Selection of a randomized, placebo controlled, double blinded crossover study design added robustness and increased the statistical power of the present trial. Dosages of n-3 PUFA for krill and fish oil treatments were kept identical which enables the direct comparison between the effects of krill and fish oil. Measurement of fatty acids in $\mathrm{RBC}$ reflects the tissue composition and is not influenced by dyslipidemic conditions. During the study, all participants kept their dietary habits and physical activities constant. None of the participants consumed any concomitant medications or supplementation or exceeded more than one fish or sea food serving per month throughout the study period which confirms that the changes in the circulatory fatty acid profile of the participants were only from the intervention, without any other dietary influence. Participants' reported compliance with each treatment was above $96 \%$ which adds strength to the results and indicates the tolerability and acceptability of the treatment capsules by the participants. The physical examination of participants at baseline and endpoint by 
the study physician for safety and well-being and the weekly telephone monitoring for compliance and adverse events added strength to the study.

\section{Limitations of the study}

The n- 6 fatty acid concentration in fish oil was higher than krill oil which could influence the effects of n-3 fatty acids and the ratio between n- 6 and n-3 fatty acids. Although we found a significant beneficial effect in fatty acid profile after krill oil consumption, the intervention period of each treatment phase was only 4 weeks long. In order to measure and achieve steady-state conditions with circulatory n-3 PUFA concentration, longer intervention periods could be recommended. Additionally, testing and comparing effects of krill oil and fish oil consumption over different time points would be very informative. The current study was a free living design which did not strictly control the macronutrient profile of each participant diet. In addition, n-3 PUFA consumption from sources other than marine foods was not strictly controlled although participants were recommended to keep their diets constant during the study. A full feeding control study with all background diets and n-3 PUFA well controlled could also be recommended.

In summary, the consumption of krill oil significantly increased plasma and RBC concentrations of EPA along with total n-3 PUFA levels; and decreased the n-6:n-3 PUFA ratio compared with fish oil and the control treatments. The results indicate that there might be a higher bioavailability of n-3 PUFA from krill oil over fish oil. Krill oil also efficiently increased the omega-3 index compared with fish oil and control. However, krill oil, similar to fish oil, consumption resulted in a slight but significant increase in total and LDL cholesterol without altering the HDL and TG, in a manner that no alterations were seen in the TC/HDL ratio. Overall, four wk consumption of krill oil was well tolerated, and could be more effective in increasing n-3 PUFA and omega-3 index than fish oil, with no indication of adverse effects.

\section{Participants and methods Participant selection}

Healthy males and premenopausal non pregnant or nursing females $(n=24)$ ages $18-49$ y were recruited by advertisement at the Richardson Centre for Functional Foods and Nutraceuticals on the University of Manitoba campus. Participants were screened and excluded if they reported any history of cancer, rheumatoid arthritis, chronic illness, cardiovascular problems, hepatobiliary and renal disease, diabetes mellitus, inflammatory bowel disease, pancreatitis, neurological/psychological disease, bleeding disorders, experienced platelet abnormalities, and gastrointestinal disorders that could interfere with fat absorption. In addition, participants were excluded if they admitted an allergy to fish or sea foods, or reported consuming supplements including $\mathrm{n}-3$ PUFA in the past 6 mo or consuming more than one fish serving per mo during the mo prior to the start of the study. Participants were included if they were nonsmokers, with serum TG levels less than $200 \mathrm{mg} / \mathrm{dL}$, total cholesterol less than $240 \mathrm{mg} / \mathrm{dL}$, LDL-cholesterol less than $160 \mathrm{mg} /$ $\mathrm{dL}$, BMI less than 28, not consuming more than one alcoholic drink/d and not taking any medications that would interfere with lipid metabolism or to control blood lipids or treat hypertension. The protocol of the study with all procedures was reviewed and approved by the Human Ethical Review Committee of the University of Manitoba (B2011: 014). All participants were explained the study protocol and written consent was obtained.

\section{Study design and intervention}

The study design was a randomized, placebo controlled, double blinded, crossover, conducted to comply with Good Clinical Practice guidelines and in accordance with the Helsinki declaration of 1975 as revised in 1983. The study included three treatment periods. Each treatment phase lasted 4 wk and was separated by washout phases of $8 \mathrm{wk}$ (Figure 1). Washout period of $8 \mathrm{wk}$ was chosen

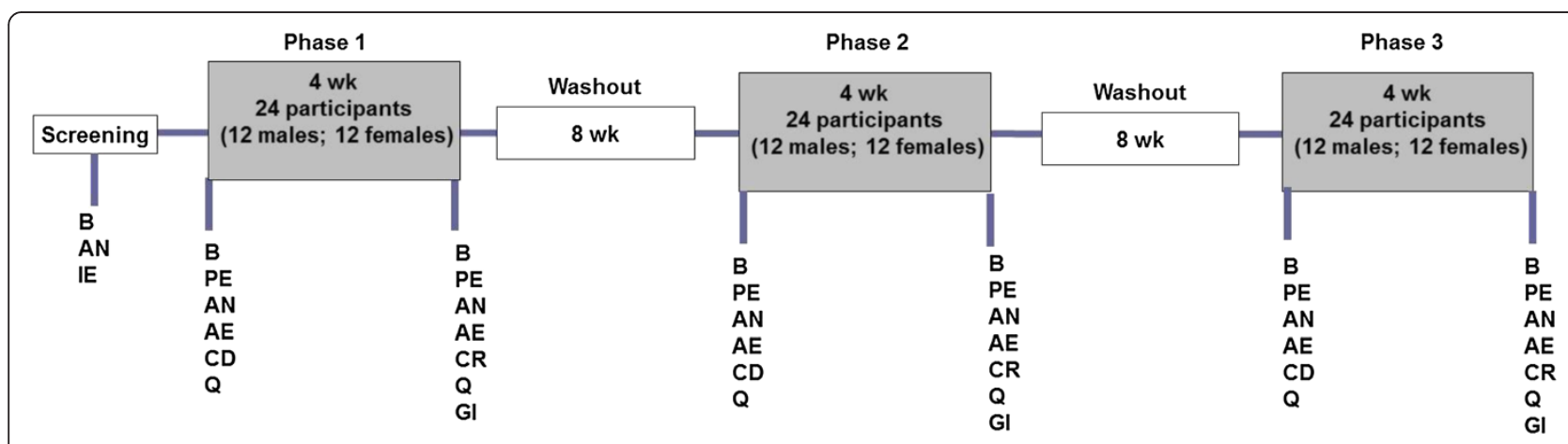

Figure 1 Schematic representation of the experimental protocol. B - $12 \mathrm{~h}$ fasted blood collection; AN - Anthropometric measurements; IE Inclusion and Exclusion criteria; PE - Physician examination; AE - Adverse events; CD - Capsule dispensation (KO or FO or corn oil capsules); CR Left over capsules return; Q - Questionnaires (Fish and sea food consumption, concomitant medications); Gl - Gastro intestinal questionnaires. 
based on results of a previous human trial with n-3 fatty acid supplementation [48]. Stratified randomization was used to allocate participants to the 3 possible treatment sequences so that an equal number of men and women were allocated to each sequence. Interventions were conducted during May and December 2011. Participants were provided with identical looking capsules containing krill, fish or corn oil on the first $d$ of each treatment phase. During each treatment period, participants consumed 6 capsules per d, 3 in the morning and 3 at night along with their meals and each capsule consisting of $500 \mathrm{mg}$ of one of the oils (a total of $3 \mathrm{~g}$ which were taken in six $500 \mathrm{mg}$ capsules, krill oil $\left(\mathrm{K} \cdot \mathrm{REAL}^{\mathrm{mm}}\right)$ was supplied by Enzymotec Ltd. and fish oil was Omevital TG 18/12 supplied by Napro Pharma, Norway). Fatty acid composition of krill, fish and corn oils are shown in Table 6. Daily doses of both krill and fish oil treatments provided $600 \mathrm{mg}$ of n-3 PUFA. However, only krill oil capsules delivered $1800 \mu \mathrm{g} / \mathrm{d}$ of astaxanthin in addition to the fatty acids.

Body weight, blood pressure, waist and hip circumference measurements and physical examinations were performed at baseline and endpoint of each treatment following standard procedures [49]. Gastrointestinal tolerability and well-being questionnaires were assessed at the endpoint of each treatment. Blood samples after $12 \mathrm{~h}$ fasting were collected at baseline and endpoint of each phase. Samples were centrifuged at $3000 \mathrm{rpm}$ for 20 min followed by separation of plasma and RBC and aliquots were stored in -80 degrees $\mathrm{C}$ until analysis. A weekly telephone questionnaire was completed by study coordinators to monitor treatment adherence and safety during the study period. Questions included; capsule intake, fish or sea food intake, adverse events and concomitant medication use. In addition, participants recorded their capsule consumption and remaining capsules were returned at the end of each phase. Compliance was calculated using the number of remaining capsules returned and written records kept by the participants.

\section{Plasma and RBC fatty acid analyses}

Plasma and RBC total lipids were extracted using the Folch method [50] which involved chloroform-methanol $(2: 1, \mathrm{v} / \mathrm{v})$ containing $0 \cdot 01 \%$ BHT (Sigma-Aldrich, Oakville, ON, Canada) and heptadecanoic acid as an internal standard (Sigma-Aldrich, Oakville, ON, Canada). Extracted fatty acids were methylated with methanolic $\mathrm{HCl}$. Fatty acid methyl esters were separated on a Supelcowax 10 column (30 m X $0.25 \mathrm{~mm}$ with $0.25 \mathrm{~mm}$ film thickness; Supelco, Bellefonte, PA, USA) using a gas chromatograph equipped with a flame ionisation detector (Bruker 430). The oven was programmed from 70 to 240 degrees $C$ with the following temperature steps $(70$ degrees $\mathrm{C}$ for $2 \mathrm{~min}$,
Table 6 Fatty acid composition of krill, fish and corn oil used in the study

\begin{tabular}{|c|c|c|c|}
\hline Fatty acid (\% of total fatty acids) & Krill oil & Fish oil & Corn oi \\
\hline C12 (Lauric) & 0.27 & 0.16 & 0.13 \\
\hline C14 (Myristic) & 11.82 & 4.49 & 0.00 \\
\hline C14:1 (Myristoleic) & 0.16 & 0.12 & 0.00 \\
\hline C15 (Pentadecanoatenoic) & 0.47 & 0.35 & 0.00 \\
\hline C16 (Palmitic) & 22.11 & 17.06 & 15.01 \\
\hline C16:1 (Palmitoleic) & 6.09 & 6.53 & 0.00 \\
\hline C17 (Margaric) & 2.02 & 0.38 & 0.00 \\
\hline C18 (Stearic) & 1.39 & 3.54 & 3.31 \\
\hline C18:1n9 (Oleic) & 13.28 & 2.62 & 1.08 \\
\hline C18:1n7 (Vaccenic) & 7.56 & 0.00 & 0.00 \\
\hline C18:2n6 (Linoleic) & 2.06 & 32.49 & 77.57 \\
\hline C18:3n6 (gamma-Linolenic) & 0.00 & 0.24 & 0.00 \\
\hline C18:3n3 (alpha-Linolenic) & 0.93 & 1.28 & 1.61 \\
\hline C18:4n3 (Moroctic) & 2.70 & 2.67 & 0.00 \\
\hline C20 (Arachidic) & 0.00 & 0.50 & 0.57 \\
\hline C20:1n9 (Eicosenoic) & 0.80 & 1.04 & 0.44 \\
\hline C20:2n6 (Eicosadienoic) & 0.41 & 0.00 & 0.00 \\
\hline C20:4n6 (Arachidonic) & 0.40 & 0.65 & 0.00 \\
\hline C20:4n3 (Eicosatetraenoic) & 0.26 & 0.80 & 0.00 \\
\hline C20:5n3 (Eicosapentaenoic) & 16.44 & 13.46 & 0.00 \\
\hline C22 (Behenic) & 0.00 & 0.73 & 0.27 \\
\hline C22:1n9 (Euricic) & 0.56 & 0.00 & 0.00 \\
\hline C22:2n9 (Docosadienoic) & 0.43 & 0.50 & 0.00 \\
\hline C22:5n3 (Docosapentaenoic) & 0.38 & 1.36 & 0.00 \\
\hline C22:6n3 (Docosahexaenoic) & 9.48 & 8.66 & 0.00 \\
\hline C24:1n9 (Nervonic) & 0.00 & 0.35 & 0.00 \\
\hline Total n-3 PUFA & 30.18 & 28.24 & 1.61 \\
\hline Total n-6 PUFA & 2.86 & 33.38 & 77.57 \\
\hline Total n-9 PUFA & 15.07 & 4.51 & 1.52 \\
\hline Total PUFA & 33.47 & 62.11 & 79.18 \\
\hline Total MUFA & 28.46 & 10.67 & 1.52 \\
\hline Total SFA & 38.07 & 27.22 & 19.30 \\
\hline
\end{tabular}

rise of 30 degrees $\mathrm{C} / \mathrm{min}, 180$ degrees $\mathrm{C}$ for $1 \mathrm{~min}$, rise of 10 degrees/min, 200 degrees $C$ for $2 \mathrm{~min}$, rise of 2 degrees $\mathrm{C} / \mathrm{min}, 220$ degrees $\mathrm{C}$ for $4 \mathrm{~min}$, rise of 20 degrees $/ \mathrm{min}$, 240 degrees for $6 \mathrm{~min}$ ). Samples were analyzed with a 20:1 split ratio; helium was used as the carrier gas with a column flow rate of $1.0 \mathrm{ml} / \mathrm{min}$. Temperatures of the injector and detector were set at 270 and 290 degrees C, respectively. Individual fatty acids were identified by comparison with known standards (NuChek Prep, Inc., Elysian, MN, USA). Individual fatty acids were calculated according to the peak area relative to the total area and expressed as the percentage of total fatty acids. 


\section{Serum lipid profile and blood cells count analyses}

Serum lipid profile including total and HDL-cholesterol and TG levels were measured using a Vitros 350 Autoanalyser (Orthoclinical diagnostics). LDL-cholesterol levels were calculated using Friedewald equation [51]. Complete blood counts were also determined using a Beckmann coulter LH780 at baseline and at endpoint of each treatment phase.

\section{Statistical analysis}

Differences between krill oil, fish oil, and placebo control interventions were analyzed for each dependent measure. Friedman Test was used to test for significant differences between treatment groups regarding the results in baseline, end-point and change between baseline and end-point. Data were analyzed using SAS statistical software, version 9.2. Values were expressed as mean \pm STD and $\mathrm{p}$ values $<0.05$ were considered significant. Safety data were examined descriptively for each arm and compared across treatments. Furthermore, statistical analyses such as Kruskal-Wallis and Friedman tests were used to identify significant differences between different phases regarding baseline result for each treatment separately and if significant differences existed between phases regarding the baseline measures (ignoring the treatment effect). These tests were done to determine the efficiency of the washout period.

\section{Additional file}

Additional file 1: Table S1. Plasma secondary fatty acids composition in individuals after interventions. Table S2: RBC secondary fatty acids composition in individuals after interventions.

\section{Abbreviations}

AHA: American heart association; CVD: Cardiovascular disease: DHA: Docosahexaenoic acid; EPA: Eicosapentaenoic acid; FDA: Food and drug administration; Gl: Gastrointestinal; GRAS: Generally regarded as safe; HDL: High-density lipoproteins; LDL: Low-density lipoproteins; MCHC: Mean corpuscular hemoglobin concentration; MCH: Mean corpuscular hemoglobin; MCV: Mean corpuscular volume.

\section{Competing interests}

VRR and PJHJ declare no conflict of interest; IE and SZ are employees of Enzymotec Ltd.

\section{Authors contributions \\ The Authors' responsibilities are as follows: IE and SZ designed the study and wrote the protocol; VRR and PJHJ coordinated and completed the trial and collected all the data, analyzed the data and statistics; VR, PJHJ, IE, SZ wrote the final draft and had primary responsibility for the final conduct. All authors read and approved the final manuscript.}

\section{Acknowledgements}

We would like to thank all the participants who conformed to the study protocol. A special thanks to the research coordinator Kimberley Robinson, at the Richardson Centre for her contribution in recruiting participants, supervision of the clinical trial, data management and statistical analysis. We would also like to thank the lab technologists Haifeng Yang for his contribution with the lab analysis for fatty acids and Jimmy Chau for contribution with sample processing for fatty acid analysis, data management and statistical analysis. Efrat Yaskil and Shiraz Vered from the University of Haifa are also acknowledged for performing the statistical analysis.

\section{Author details}

${ }^{1}$ Richardson Centre for Functional Foods and Nutraceuticals, Winnipeg, Canada. ${ }^{2}$ Department of Human Nutritional Sciences, University of Manitoba, Winnipeg, Canada. ${ }^{3}$ Enzymotec Ltd. P.O.B 6, Migdal HaEmeq, Israel.

Received: 18 September 2013 Accepted: 19 November 2013 Published: 5 December 2013

\section{References}

1. Burr ML, Fehily AM, Gilbert JF, Rogers S, Holliday RM, Sweetnam PM, Elwood PC, Deadman NM: Effects of changes in fat, fish, and fibre intakes on death and myocardial reinfarction: diet and reinfarction trial (DART). Lancet 1989, 2:757-761.

2. Harris WS: The omega-3 index as a risk factor for coronary heart disease. Am J Clin Nutr 2008, 87:1997S-2002S.

3. He K, Rimm EB, Merchant A, Rosner BA, Stampfer MJ, Willett WC, Ascherio A: Fish consumption and risk of stroke in men. JAMA 2002, 288:3130-3136.

4. He K, Song Y, Daviglus ML, Liu K, Van Horn L, Dyer AR, Greenland P: Accumulated evidence on fish consumption and coronary heart disease mortality: a meta-analysis of cohort studies. Circulation 2004, 109:2705-2711.

5. Kris-Etherton PM, Harris WS, Appel $\amalg$, American Heart Association: Nutrition C: Fish consumption, fish oil, omega-3 fatty acids, and cardiovascular disease. Circulation 2002, 106:2747-2757.

6. Marckmann P, Gronbaek M: Fish consumption and coronary heart disease mortality: A systematic review of prospective cohort studies. Eur J Clin Nutr 1999, 53:585-590.

7. Tou JC, Jaczynski J, Chen YC: Krill for human consumption: nutritional value and potential health benefits. Nutr Rev 2007, 65:63-77.

8. Monograph: Krill oil: Monograph. Altern Med Rev 2010, 15:84-86.

9. Ruggiero-Lopez D, Servetto C, Lopez E, Lenoir D, Alallon W, Biol MC, Louisot $P$, Martin A: Comparative effects of dietary corn, fish and krill oils on intestinal glycosylation. Biochem Mol Biol Int 1994, 33:1001-1010.

10. Maki KC, Reeves MS, Farmer M, Griinari M, Berge K, Vik H, Hubacher R, Rains TM: Krill oil supplementation increases plasma concentrations of eicosapentaenoic and docosahexaenoic acids in overweight and obese men and women. Nutr Res 2009, 29:609-615.

11. Bunea R, El Farrah K, Deutsch L: Evaluation of the effects of neptune krill oil on the clinical course of hyperlipidemia. Altern Med Rev 2004, 9:420-428.

12. Deutsch $L$ : Evaluation of the effect of neptune krill oil on chronic inflammation and arthritic symptoms. J Am Coll Nutr 2007, 26:39-48.

13. Sampalis F, Bunea R, Pelland MF, Kowalski O, Duguet N, Dupuis S: Evaluation of the effects of neptune krill oil on the management of premenstrual syndrome and dysmenorrhea. Altern Med Rev 2003, 8:171-179.

14. Wijendran V, Huang MC, Diau GY, Boehm G, Nathanielsz PW, Brenna JT: Efficacy of dietary arachidonic acid provided as triglyceride or phospholipid as substrates for brain arachidonic acid accretion in baboon neonates. Pediatr Res 2002, 51:265-272.

15. Kidd PM: Omega-3 DHA and EPA for cognition, behavior, and mood: clinical findings and structural-functional synergies with cell membrane phospholipids. Altern Med Rev 2007, 12:207-227.

16. Batetta B, Griinari M, Carta G, Murru E, Ligresti A, Cordeddu L, Giordano E, Sanna F, Bisogno T, Uda S, et al: Endocannabinoids may mediate the ability of (n-3) fatty acids to reduce ectopic fat and inflammatory mediators in obese Zucker rats. J Nutr 2009, 139:1495-1501.

17. Ulven SM, Kirkhus B, Lamglait A, Basu S, Elind E, Haider T, Berge K, Vik H, Pedersen I: Metabolic effects of krill oil are essentially similar to those of fish oil but at lower dose of EPA and DHA, in healthy volunteers. Lipids 2011, 46:37-46.

18. Schuchardt JP, Schneider I, Meyer H, Neubronner J, von Schacky C, Hahn A: Incorporation of EPA and DHA into plasma phospholipids in response to different omega-3 fatty acid formulations-a comparative bioavailability study of fish oil vs. krill oil. Lipids Health Dis 2011, 10:145.

19. Banni S, Carta G, Murru E, Cordeddu L, Giordano E, Sirigu AR, Berge K, Vik H, Maki KC, Di Marzo V, Griinari M: Krill oil significantly decreases 2arachidonoylglycerol plasma levels in obese subjects. Nutr Metab (Lond) 2011, 8:7. 
20. Griffin BA: How relevant is the ratio of dietary $n-6$ to $n-3$ polyunsaturated fatty acids to cardiovascular disease risk? Evidence from the OPTILIP study. Curr Opin Lipidol 2008, 19:57-62.

21. Krauss RM, Eckel RH, Howard B, Appel LJ, Daniels SR, Deckelbaum RJ, Erdman JW Jr, Kris-Etherton P, Goldberg IJ, Kotchen TA, et al: AHA Dietary Guidelines: revision 2000: A statement for healthcare professionals from the nutrition committee of the American heart association. Stroke 2000, 31:2751-2766.

22. de Lorgeril M, Salen P, Martin JL, Monjaud I, Delaye J, Mamelle N: Mediterranean diet, traditional risk factors, and the rate of cardiovascular complications after myocardial infarction: final report of the Lyon diet heart study. Circulation 1999, 99:779-785.

23. Wood DA, Riemersma RA, Butler S, Thomson M, Macintyre C, Elton RA, Oliver MF: Linoleic and eicosapentaenoic acids in adipose tissue and platelets and risk of coronary heart disease. Lancet 1987, 1:177-183.

24. Gillum RF, Mussolino M, Madans $\mathrm{JH}$ : The relation between fish consumption, death from all causes, and incidence of coronary heart disease. the NHANES I Epidemiologic Follow-up Study. J Clin Epidemiol 2000, 53:237-244.

25. Guallar E, Hennekens CH, Sacks FM, Willett WC, Stampfer MJ: A prospective study of plasma fish oil levels and incidence of myocardial infarction in U.S. male physicians. J Am Coll Cardiol 1995, 25:387-394.

26. Werner A, Havinga R, Kuipers F, Verkade HJ: Treatment of EFA deficiency with dietary triglycerides or phospholipids in a murine model of extrahepatic cholestasis. Am J Physiol Gastrointest Liver Physiol 2004, 286:G822-832.

27. Di Marzo V, Griinari M, Carta G, Murru E, Ligresti A, Cordeddu L, Giordano E, Bisogno T, Collu M, Betetta B, Uda S, Berge K, Banni S: Dietary krill increases docosahexaenoic acid and reduces 2-arachidonoylglycerol but not $\mathrm{N}$-acylethanolamine levels in the brain of obese zucker rats. International Dairy Journal 2010, 20:231-235

28. Graf BA, Duchateau GS, Patterson AB, Mitchell ES, van Bruggen $P$, Koek JH, Melville S, Verkade HJ: Age dependent incorporation of 14C-DHA into rat brain and body tissues after dosing various 14C-DHA-esters. Prostaglandins Leukot Essent Fatty Acids 2010, 83:89-96.

29. Carnielli VP, Verlato G, Pederzini F, Luijendijk I, Boerlage A, Pedrotti D, Sauer PJ: Intestinal absorption of long-chain polyunsaturated fatty acids in preterm infants fed breast milk or formula. Am J Clin Nutr 1998, 67:97-103.

30. Harris WS, Von Schacky C: The Omega-3 Index: a new risk factor for death from coronary heart disease? Prev Med 2004, 39:212-220.

31. Paganelli F, Maixent JM, Duran MJ, Parhizgar R, Pieroni G, Sennoune S: Altered erythrocyte $n-3$ fatty acids in Mediterranean patients with coronary artery disease. Int J Cardiol 2001, 78:27-32.

32. Katan MB, Deslypere JP, van Birgelen AP, Penders M, Zegwaard M: Kinetics of the incorporation of dietary fatty acids into serum cholesteryl esters, erythrocyte membranes, and adipose tissue: an 18-month controlled study. J Lipid Res 1997, 38:2012-2022.

33. Rupp H, Wagner D, Rupp T, Schulte LM, Maisch B: Risk stratification by the "EPA + DHA level" and the "EPA/AA ratio" focus on anti-inflammatory and antiarrhythmogenic effects of long-chain omega-3 fatty acids. Herz 2004, 29:673-685.

34. Albert CM, Campos H, Stampfer MJ, Ridker PM, Manson JE, Willett WC, Ma J: Blood levels of long-chain n-3 fatty acids and the risk of sudden death. N Engl J Med 2002, 346:1113-1118.

35. von Schacky C, Harris WS: Cardiovascular risk and the omega-3 index. J Cardiovasc Med (Hagerstown) 2007, 8(Suppl 1):S46-49.

36. Harris WS: n-3 fatty acids and serum lipoproteins: human studies. Am J Clin Nutr 1997, 65:1645S-1654S.

37. Kris-Etherton PM, Hill AM: N-3 fatty acids: food or supplements? J Am Diet Assoc 2008, 108:1125-1130.

38. Harris WS: Fish oils and plasma lipid and lipoprotein metabolism in humans: a critical review. J Lipid Res 1989, 30:785-807.

39. Sadzuka Y, Sugiyama I, Miyashita M, Ueda T, Kikuchi S, Oshiro E, Yano A, Yamada H: Beneficial effects by intake of Euphausiacea pacifica on high-fat diet-induced obesity. Biol Pharm Bull 2012, 35:568-572.

40. GISSI-Prevenzione Investigators: Dietary supplementation with n-3 polyunsaturated fatty acids and vitamin $\mathrm{E}$ after myocardial infarction: results of the GISSI-Prevenzione trial. Gruppo Italiano per lo Studio della Sopravvivenza nell'Infarto miocardico. Lancet 1999, 354:447-455.

41. Grimsgaard S, Bonaa KH, Hansen JB, Nordoy A: Highly purified eicosapentaenoic acid and docosahexaenoic acid in humans have similar triacylglycerol-lowering effects but divergent effects on serum fatty acids. Am J Clin Nutr 1997, 66:649-659.

42. Mori TA, Burke V, Puddey IB, Watts GF, O'Neal DN, Best JD, Beilin LJ: Purified eicosapentaenoic and docosahexaenoic acids have differential effects on serum lipids and lipoproteins, LDL particle size, glucose, and insulin in mildly hyperlipidemic men. Am J Clin Nutr 2000, 71:1085-1094.

43. Schwellenbach $\sqcup$, Olson KL, McConnell KJ, Stolcpart RS, Nash JD, Merenich JA: The triglyceride-lowering effects of a modest dose of docosahexaenoic acid alone versus in combination with low dose eicosapentaenoic acid in patients with coronary artery disease and elevated triglycerides. J Am Coll Nutr 2006, 25:480-485.

44. Kris-Etherton PM, Harris WS, Appel $\amalg$, Nutrition C: Fish consumption, fish oil, omega-3 fatty acids, and cardiovascular disease. Arterioscler Thromb Vasc Biol 2003, 23:e20-30.

45. Contacos C, Barter PJ, Sullivan DR: Effect of pravastatin and omega-3 fatty acids on plasma lipids and lipoproteins in patients with combined hyperlipidemia. Arterioscler Thromb 1993, 13:1755-1762.

46. Sanders TA, Gleason K, Griffin B, Miller GJ: Influence of an algal triacylglycerol containing docosahexaenoic acid (22: $6 n-3)$ and docosapentaenoic acid (22: $5 n-6)$ on cardiovascular risk factors in healthy men and women. Br J Nutr 2006, 95:525-531.

47. Normen L, Shaw CA, Fink CS, Awad AB: Combination of phytosterols and omega-3 fatty acids: a potential strategy to promote cardiovascular health. Curr Med Chem Cardiovasc Hematol Agents 2004, 2:1-12.

48. Cao J, Schwichtenberg KA, Hanson NQ, Tsai MY: Incorporation and clearance of omega-3 fatty acids in erythrocyte membranes and plasma phospholipids. Clin Chem 2006, 52:2265-2272.

49. van der Kooy K, Seidell JC: Techniques for the measurement of visceral fat: a practical guide. Int J Obes Relat Metab Disord 1993, 17:187-196.

50. Folch J, Lees M, Sloane Stanley GH: A simple method for the isolation and purification of total lipides from animal tissues. J Biol Chem 1957, 226:497-509.

51. Friedewald WT, Levy RI, Fredrickson DS: Estimation of the concentration of low-density lipoprotein cholesterol in plasma, without use of the preparative ultracentrifuge. Clin Chem 1972, 18:499-502

doi:10.1186/1476-511X-12-178

Cite this article as: Ramprasath et al.: Enhanced increase of omega-3 index in healthy individuals with response to 4-week n-3 fatty acid supplementation from krill oil versus fish oil. Lipids in Health and Disease $201312: 178$.

\section{Submit your next manuscript to BioMed Central and take full advantage of:}

- Convenient online submission

- Thorough peer review

- No space constraints or color figure charges

- Immediate publication on acceptance

- Inclusion in PubMed, CAS, Scopus and Google Scholar

- Research which is freely available for redistribution 